\section{SAT0118 COMPARATIVE EFFECTIVENESS OF TOCILIZUMAB IN COMBINATION WITH METHOTREXATE VERSUS TUMOR NECROSIS FACTOR INHIBITORS (TNFIS) IN COMBINATION WITH METHOTREXATE IN PATIENTS WITH RHEUMATOID ARTHRITIS WITH PRIOR EXPOSURE TOTNFIS}

D. A. Pappas ${ }^{1,2}$, T. Blachley ${ }^{2}$, S. Zlotnick ${ }^{3}$, J. H. Best ${ }^{3}$, K. Emeanuru² ${ }^{2}$ J. M. Kremer ${ }^{2,4}$. ${ }^{1}$ Columbia University, New York, United States of America; ${ }^{2}$ Corrona, LLC, Waltham, United States of America; ${ }^{3}$ Genentech, Inc, South San Francisco, United States of America; ${ }^{4}$ Albany Medical College and The Center for Rheumatology, Albany, United States of America

Background: Clinical studies have demonstrated the efficacy of tocilizumab (TCZ) administered with methotrexate (MTX) in improving rheumatoid arthritis (RA) disease activity in patients who have had an inadequate response to tumor necrosis factor inhibitors (TNFis).

Objectives: To compare the effectiveness of TCZ + MTX with that of TNFis + MTX in patients with RA who had prior exposure to TNFis in routine clinical practice. Methods: Eligible participants were TCZ-naiive patients from the Corrona RA registry who initiated TCZ + MTX or a TNFi + MTX after January 1, 2010 and had a 6 -month follow-up visit. Patients in both groups must have used $\geq 1 \mathrm{TNFi}$, had a Clinical Disease Activity Index (CDAl) score available at initiation (baseline) and 6 months and had a CDAl score $>10$ at baseline. The primary outcome was mean change in CDAl from baseline to 6 months. Secondary outcomes included achievement of low disease activity ( $L D A ; C D A I \leq 10)$ and mean change in modified Health Assessment Questionnaire (mHAQ) at 6 months. Patients were grouped by baseline MTX dose ( $\leq 10 \mathrm{mg} ;>10$ to $\leq 15 \mathrm{mg} ;>15$ to $\leq 20 \mathrm{mg}$; $>20 \mathrm{mg}$ ); outcomes were compared between patients initiating TCZ and those initiating a TNFi overall and within each MTX dose group using propensity score (PS)-trimmed populations. As a sensitivity analysis, TCZ and TNFi initiators in each group were PS-matched $1: 1$ and outcomes were assessed in the matched populations. Linear and logistic regression models were estimated in the trimmed and matched populations, adjusting for covariates not balanced after PS trimming or matching, respectively. Results: A total of 415 TCZ + MTX initiators and 725 TNFi + MTX initiators met the inclusion criteria prior to PS trimming or matching. The overall trimmed population included 402 TCZ + MTX initiators and 703 TNFi + MTX initiators. In the trimmed population, patient demographics were generally comparable between $\mathrm{TCZ}+\mathrm{MTX}$ and TNFi + MTX initiators; the mean age was 57.1 years in the TCZ + MTX group and 57.7 years in the TNFi + MTX group, the majority of patients in both groups were female $(\geq 80 \%)$ and white $(\geq 82 \%)$ and the mean duration of RA was 11.8 and 10.5 years in the TCZ + MTX and TNFi + MTX groups, respectively. Higher proportions of patients initiating TCZ had received $\geq 2$ prior biologics $(66.0 \%$ to $76.3 \%)$ compared with those initiating a TNFi (33.2\% to $42.2 \%)$ across all MTX dose groups. Patients initiating TCZ had higher mean baseline CDAl scores (26.5 to 29.3) than those initiating a TNFi (24.7 to 27.5). Patients in both cohorts had improvements in CDAI and $\mathrm{mHAQ}$ scores and achieved LDA in similar proportions at 6 months regardless of baseline MTX dose (Fig 1). Results were comparable between TCZ and TNFi initiators across all MTX groups in the trimmed population after adjustment for potential confounding variables. Similar results were observed in the PS-matched cohorts.

Conclusion: In this real-world population of US patients with RA who had prior TNFi exposure, there was no statistically significant or clinically meaningful difference in the effectiveness of therapy in patients who initiated TCZ + MTX compared with TNFi + MTX

Acknowledgments : This study was sponsored by Corrona, LLC. Corrona is supported through contracted subscriptions with multiple pharmaceutical companies. The abstract was a collaborative effort between Corrona and Genentech, Inc., with financial support provided by Genentech, Inc.

Disclosure of Interests: : Dimitrios A Pappas: None declared, Taylor Blachley Employee of: Corrona, LLC, Steve Zlotnick Shareholder of: Genentech, Inc., Employee of: Genentech, Inc., Jennie H. Best Shareholder of: Genentech, Inc., Employee of: Genentech, Inc., Kelechi Emeanuru Employee of: Corrona, LLC employment, Joel M Kremer Shareholder of: May own stocks and opinions, Grant/ research support from: Research and consulting fees from AbbVie Inc., Consultant of: AbbVie, Amgen, BMS, Genentech, Inc., Gilead, GSK, Lilly, Pfizer, Regeneron and Sanofi, Employee of: Corrona, LLC employee

DOI: 10.1136/annrheumdis-2020-eular.588

\section{SAT0119 PARADOXICAL NEUTROPHIL ACTIVATION BY ANTI-IL6 THERAPY:TRANSCRIPTOME ANALYSIS SHOWS A RATIONALE FOR DERMATOLOGICAL ADVERSE REACTIONS AND DECREASED NEUTROPHIL COUNTS AFTER TOCILIZUMAB TREATMENT}

M. Sakamoto ${ }^{1}$, A. Senoh ${ }^{2}$, Y. Sato ${ }^{3}$, H. lijima ${ }^{3}$, M. Yamaguchi ${ }^{2}$, T. Higuchi ${ }^{1}$, Y. Koyama'. ' Japanese Red Cross Okayama Hospital, Division of Rheumatology, Center for Autoimmune diseases, Okayama, Japan; ${ }^{2}$ Japanese
Red Cross Okayama Hospital, Division of Dermatology, Okayama, Japan; ${ }^{3} D N A$ Chip Research Inc, Tokyo, Japan

Background: Skin rashes as a side effect of Tocilizumab therapy (TCZ- Tx) has not been paid much attention, because the incidence was only $1 \sim 2 \%$ in the drug information sheets. However, we experienced several RA cases with development of various skin rashes associated with neutrophil activation after TCZ-Tx. On the other hand, it is well known that the neutrophil counts in peripheral blood decreases after TCZ-Tx, whereas it does not affect the rate of serious infections. The detailed mechanism is still unclear.

Objectives: To detect the characteristics of the changes in gene expressions of peripheral blood associated with TCZ-Tx and the development of skin rashes as its side effect.

Figure 1. PS Trimmed Unadjusted Outcomes at 6 Months Stratified by Baseline MTX Dose (A) Mean Change in CDAI. (B) Mean Change in mHAQ. (C) Proportion of Patients Who Achieved LDA.

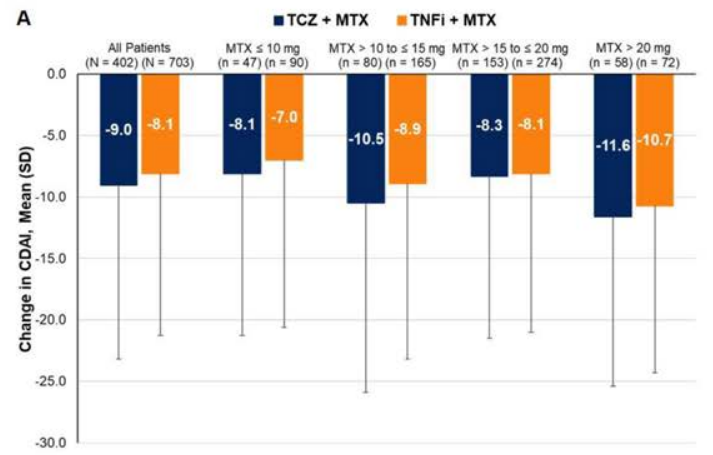

B

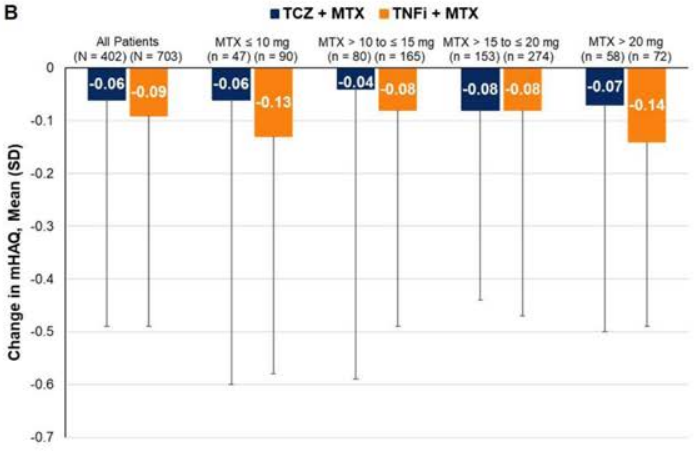

C

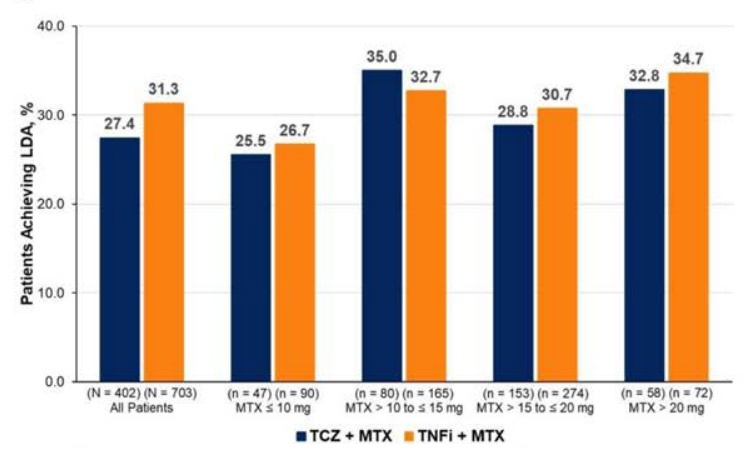

$\mathrm{CDAl}$, clinical disease activity index; $\mathrm{LDA}$, low disease activity; $\mathrm{mHAQ}$, modified health assessment questionnaire; MTX, methotrexate; PS, propensity score; TCZ, tocilizumab; TNFi, tumor necrosis factor inhibitor

Methods: Total of 14 RA patients with TCZ-Tx were included. Among them, 4 patients developed TCZ-related rashes (group S) and 10 patients did not show any side effects (group C). Peripheral whole blood at just before (pre) and 3 months after (post) TCZ-Tx from each patient were subjected to the analysis. Total RNAs were extracted with PAXgene miRNA kit and analyzed with next-generation sequencing. First, group $C$ was investigated for the normal response to TCZ-Tx. Differentially expressed genes (DEGs) were selected by paired comparison (post vs. pre). And then, enrichment analysis using gene ontology (GO) terms were performed. Second, to explore the characteristics of group $\mathrm{S}$, all expressed genes in 14 cases at just before TCZ-TX 